\title{
POVOS INDÍGENAS, MAPEAMENTOS PARTICIPATIVOS E POLÍTICA DE GESTÃO TERRITORIAL: O CASO DO SEMIÁRIDO BRASILEIRO
}

INDIGENOUS PEOPLE, PARTICIPATORY MAPPING AND TERRITORIAL MANAGEMENT POLICY: THE BRAZILIAN SEMIARID

\section{Lara Erendira Almeida de Andrade}

laraerendira@yahoo.com.br

(Doutoranda em Antropologia/UFPE; bolsista Capes)

Marcelino Soyinka Santos Dantas

(Mestre em ecologia pelo Instituto Nacional de Pesquisas da Amazônia; Indigenista/FUNAI)

\section{RESUMO}

O presente artigo tem por objetivo refletir duas experiências que foram desenvolvidas no contexto de implementação Política Nacional de Gestão Territorial e Ambiental em Terras Indígenas (PNGATI). Referimo-nos aos projetos de realização dos Planos de Gestão Territorial e Ambiental (PGTA) das Terras Indígenas Pankararu Entre Serras e Kapinawá, ambas em Pernambuco, semiárido pernambucano, nas quais os autores participaram enquanto membros da equipe. Propomo-nos a refletir de forma mais detalhada sobre como os processos de mapeamento participativos foram desenvolvidos e seus respectivos resultados.

Palavras-Chave: política pública de gestão territorial. Mapeamento participativo. Povos indígenas no semiárido.

\begin{abstract}
The present article aims to reflect on two experiences developed in the context of implementation of the National Policy on Territorial and Environmental Management in Indigenous Lands (PNGATI). We refer to the realization of the Territorial and Environmental Management Plans (PGTA) of the Indigenous Lands Pankararu Entre Serras and Kapinawá, both in Pernambuco, semiarid region, in which the authors participated as members of the team. We propose a detailed reflection on participatory mapping processes and their respective results.
\end{abstract}

Keywords: Public policy of territorial management. Participatory mapping. Peoples in the semi-arid. 


\section{INTRODUÇÃO}

Historicamente, os mapas foram utilizados principalmente como instrumento de dominação e controle de territórios, notadamente por meio de seu uso por Estados Nação. Aperfeiçoados tecnicamente ao longo dos séculos por navegadores e comerciantes com o intuito de ampliar suas rotas, consolidaram-se como ferramenta estratégica de domínio de territórios "desconhecidos" por colonizadores a partir das chamadas grandes navegações, em detrimento da existência e territorialidades de povos autóctones. Nesse processo histórico, percebe-se que o mapa tem sido uma das ferramentas estratégicas durante a colonização e nos períodos seguintes de formação dos países das Américas, consistindo num dos instrumentos de invisibilização para dominação dos povos indígenas pelos Estados recém instalados e surgidos no chamado Novo Mundo. Entretanto, nas últimas décadas, temos assistido à ressignificação e utilização dessa mesma ferramenta por estes atores antes invisibilizados, justamente como instrumento político na luta pelos seus direitos territoriais, conforme elucidaremos a seguir.

Os avanços tecnológicos no instrumental de geotecnologias ocorridos neste período - popularização dos computadores pessoais, advento da internet, criação e disseminação do Sistema de Posicionamento Global (GPS), apenas para citar alguns exemplos - permitiram uma maior diversificação no perfil de profissionais e demais pessoas envolvidas na confecção de mapas, o que também possibilitou uma maior descentralização da produção cartográfica, antes concentrada principalmente em agentes e agências estatais. Essa movimentação veio ao encontro das demandas de movimentos sociais diversos que vinham buscando visibilidade às suas lutas por reconhecimento de seus modos de vida e existência frente diversas investidas sobre seus territórios, promovidas por particulares e/ou fomentadas pelo mesmo Estado. (ALMEIDA, 2012).

Essas lutas sociais por reconhecimento alcançaram seu ápice na constituinte de 1988, que resultou na incorporação ao texto constitucional dispositivos fundamentais para a garantia legal destas territorialidades diferenciadas no Estado Brasileiro ${ }^{1}$. Nesse sentido, o período imediatamente posterior à promulgação da constituição de 1988, na década de 1990, caracteriza-se por um boom de iniciativas em que, estes grupos que foram alvo de dominação ao longo de séculos, também começam a utilizar os mapas como ferramenta para conferir visibilidade às suas territorialidades frente ao Estado. Utiliza-se assim deste meio como um instrumento de "contra-ataque" nessa chamada "guerra dos mapas", para utilizar os termos de Alfredo Wagner de Almeida (1994) ao tratar do caso de Carajás (PA). No caso mencionado as populações locais produzem seus próprios mapas em contraposição às lógicas desenvolvimentistas e colonizadoras do Estado que visavam ocupar os territórios supostamente vazios ocupados por atores sociais diversos.

Neste artigo buscamos tratar em certa medida desta "guerra de mapas" num contexto muito específico: o de processos de mapeamento participativo em projetos de gestão territorial e ambiental de terras indígenas no semiárido brasileiro. Trazemos esta reflexão a partir de projetos pilotos dos quais participamos enquanto equipe técnica (indigenistas), no contexto de implementação da Política Nacional de Gestão Territorial e Ambiental em Terras Indígenas (PNGATI). Trata-se aqui de forma particular dois destes projetos que visavam a elaboração de Planos de Gestão Territorial e Ambiental (PGTAs) das de Terras Indígenas (TIs) Pankararu Entre Serras e Kapinawá, ambas em Pernambuco.

Para pensar as questões envolvidas o texto foi organizado da seguinte forma: inicialmente refletimos sobre como os processos de mapeamento participativo foram inseridos nas políticas públicas, particularmente na PNGATI; 
em seguida, tratamos de forma mais geral sobre aspectos relevantes para pensar a gestão no contexto do semiárido brasileiro. E, por fim, refletimos sobre a metodologia adotada e os resultados dos trabalhos.

\section{MAPEAMENTO PARTICIPATIVO COMO FERRAMENTA GESTÃO TERRITORIAL E AMBIENTAL DE TERRAS INDÍGENAS NA POLÍTICA DE ESTADO}

Oriunda de um contexto complexo de articulação entre ambientalismo e lutas por direitos sociais e reconhecimento étnico que ganha impulso a partir da década de 1980, podemos dizer, de maneira simplificada e bastante resumida, que a Política Nacional de Gestão Ambiental e Territorial (PNGATI) surgiu, fundamentalmente, a partir de demanda de parte do movimento indígena para que o Estado brasileiro reconhecesse e apoiasse as ações daquilo que se chamou de "gestão" do território e do ambiente, já realizadas pelos próprios indígenas em suas áreas. (APIB, 2016). Essa política surge igualmente como resultado de um longo processo de articulação e tensões entre movimentos indígenas e ambientalistas, reconhecendo que a gestão indígena de seus territórios notoriamente tem resultado em formas menos danosas ao meio ambiente do que as formas convencionais de ocupação das áreas circundantes. (ALMEIDA, 2012; BAVARESCO; MENEZES 2014; MACIEL, 2015). Importante lembrar que tais ações beneficiam toda a sociedade, a exemplo do caso dos "serviços ambientais prestados" pelos baixos índices de desmatamento no interior das TIs quando comparados com seu entorno ${ }^{2}$.

Como mencionado na introdução, as experiências de mapeamento participativo deram e ainda dão outro sentido possível aos mapas. Acselrad e Coli (2008) nos ajudam a compreender essa mudança:

\footnotetext{
Para Herlihy e Knapp (2003), o mapeamento participativo é aquele que reconhece o conhecimento espacial e ambiental de populações locais e os insere em modelos mais convencionais de conhecimento. Suas raízes metodológicas estariam ligadas ao que as agências promotoras do "desenvolvimento" chamaram de "observação participativa" e "metodologias de pesquisa colaborativa". Assim é que métodos de pesquisa participativa combinados com tecnologias como as dos SIG - Sistemas de Informação Geográfica, dos Global Positioning Systems (GPS) e do sensoriamento remoto foram adotados para a elaboração dos mapas, gerando um novo horizonte de produção e uso de tais instrumentos de representação espacial (Herlihy e Knapp, 2003), assim como também um novo espaço de intervenção para as referidas agências de desenvolvimento. (ACSELRAD; COLI, 2008, p.14).
}

Nesse sentido, após um longo percurso de conferências e discussões em diversos espaços de articulação interinstitucional e de participação social dos povos indígenas, o decreto que instaurou a PNGATI foi publicado no dia 5 de junho de 2012, oficializando sua criação. (BAVARESCO; MENEZES, 2014). Para alcançar os objetivos a que se propõe o decreto de implementação dessa política, os processos de mapeamentos colaborativos alcançaram destaque, sendo incluídos como ferramentas para auxiliar nos processos de gestão. No Capitulo I,Disposições Preliminares do próprio decreto o mapeamento é apontado como ferramenta privilegiada deste processo:

Art. 2o São ferramentas para a gestão territorial e ambiental de terras indígenas o etnomapeamento e o etnozoneamento. 
Parágrafo único. Para fins deste Decreto, consideram-se: I - Etnomapeamento: mapeamento participativo das áreas de relevância ambiental, sociocultural e produtiva para os povos indígenas, com base nos conhecimentos e saberes indígenas; e II - Etnozoneamento: instrumento de planejamento participativo que visa à categorização de áreas de relevância ambiental, sociocultural e produtiva para os povos indígenas, desenvolvido a partir do etnomapeamento.(Decreto $\mathrm{n}^{\circ} 7.747$, de 5 de junho de 2012, grifos nossos).

Esses etnomapeamentos, como são denominados, são idealizados como uma das etapas da construção dos Planos de Gestão Territorial e Ambiental (PGTA), uma das principais ferramentas para a implementação da política PNGATI nas TIs. Em publicação, que orienta a elaboração dos PGTAs, são enumerados os passos de desenvolvimentos dos planos: (1) etapa I: sensibilização e mobilização; (2) etapa II: diagnóstico, que prevê diagnóstico participativo e etnomapeamento; e (3) etapa III: planejamento, que prevê o planejamento e a priorização de ações e projetos voltados à resolução de problemas ou desenvolvimento de potencialidades identificados na etapa de diagnóstico (cf. FUNAI, 2013, p.9). Na etapa do diagnóstico, são enumerados os aspectos de devem ser trabalhados nos referidos mapeamentos:

[...] f) Levantamento, mapeamento (representação gráfica) e caracterização das formas de uso e ocupação do território de acordo com as categorias indígenas de classificação do ambiente e das paisagens. Deve-se considerar os espaços associados à habitação, economia, cosmologia e outras áreas de importância cultural, além da intensidade e temporalidade no manejo e uso de recursos naturais e outros aspectos considerados relevantes no contexto local; g) Levantamento, mapeamento e caracterização das atividades produtivas desenvolvidas na terra indígena, identificando-se suas potencialidades quanto à segurança alimentar e nutricional e a geração de renda, sua sustentabilidade e possíveis impactos socioambientais; h) Levantamento, mapeamento e caracterização de impactos, passivos, ameaças e conflitos socioambientais na TI e no entorno. (FUNAI, 2013, p.15, grifos nossos).

Como vemos, a partir do que estabelecem as orientações para a produção do diagnóstico no contexto do PGTA e para a execução da PNGATI, o mapeamento participativo é uma de suas ferramentas centrais.

O que foi posto acima nos faz levantar algumas questões que giram em torno da ideia que os mapeamentos participativos, que vinham sendo utilizados como ferramenta de "contra-ataque" dos movimentos frente às investidas sobre seus territórios, passaram a ser incorporados como instrumento de política pública do Estado. Assim nos perguntamos: qual a liberdade que os movimentos têm nesse contexto? Seria essa mais uma forma de cooptação do Estado sobre os movimentos? Mais uma forma controle sobre seus territórios? Ou, por outro lado, uma forma de pressão dos movimentos sobre o Estado?

\section{GESTÃO TERRITORIAL E AMBIENTAL EM TERRAS INDÍGENAS NO NORDESTE BRASILEIRO}

Antes de adentrar a reflexão sobre os processos de mapeamento propriamente ditos, achamos importante situar os contextos sociopolíticos e de políticas públicas em que se situam as experiências aqui trabalhadas. 
Um primeiro aspecto importante a ser mencionado é que projetos de que trabalhem o contexto da gestão territorial e ambiental em territórios indígenas no Nordeste brasileiro são ainda muito incipientes. Em outras regiões do país, especialmente na região amazônica, ações neste sentido são desenvolvidas há décadas, com saberes, metodologias e publicização de resultados já bem consolidados - são mais oitenta planos de gestão já construídos. (MACIEL 2015). Na região Nordeste temos duas experiências pioneiras desenvolvidas no início dos anos 2010, ambas no bioma da mata atlântica e publicadas em livros: com os Potiguara no litoral norte da Paraíba (CARDOSO; GUIMARÃES, 2012) e com os Pataxó no extremo sul da Bahia (CARDOSO; PINHEIRO, 2012). Os projetos refletidos neste texto são os primeiros ocorridos em região que abrange o bioma da caatinga (que é o predominante na região), e foram realizados apenas nos últimos quatro anos.

Afinal, as políticas para a conservação da biodiversidade, apesar dos avanços nas últimas décadas para incluir a sociodiversidade, ainda possuem forte influência do chamado "mito da natureza intocada" (DIEGUES, 2004), reflexo da pretensa dicotomia natureza/cultura, à qual também está associada a imagem dos indígenas. Essa noção reflete-se nas ações do Estado, que enfatizam políticas para proteção naquelas áreas mais próximas de seu pretenso estágio 'prístino' - ou seja, no bioma amazônico, ícone desta "natureza intocada" e dos "índios puros". Um exemplo deste processo é a efetivação dos direitos territoriais indígenas: 93\% das Terras Indígenas (TIs) regularizadas situam-se na Amazônia, apesar de $62 \%$ da população indígena viver fora da região Norte. Apresentamos a distribuição no gráfico a seguir:

Figura 1 - População indígena por Região - Brasil/2010

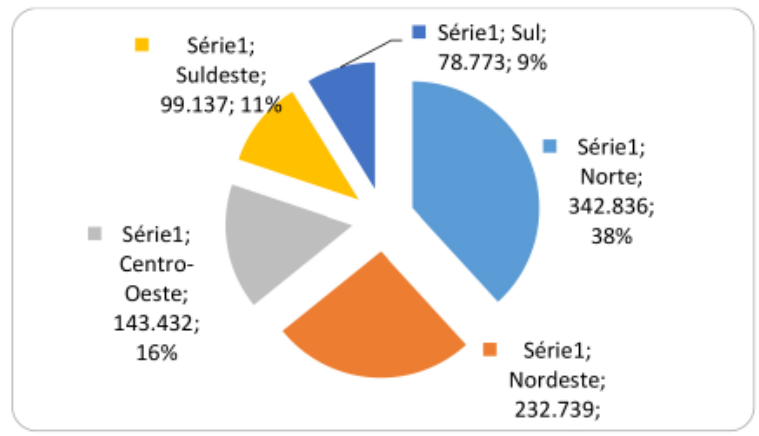

Fonte: IBGE, Censo demográfico 2010

Os dados sobre o Nordeste são exemplares neste sentido: a região convive com a escassez de iniciativas estatais e não estatais de apoio à conservação ou aos direitos das populações indígenas que aí habitam. Não é de estranhar que a ela esteja associado o imaginário da seca, da pobreza e do índio "integrado". O próprio bioma, a caatinga, compõe tal imaginário, e é reconhecidamente preterido em políticas de conservação, sendo o bioma que possui menor proporção de sua área protegida através de Unidades de Conservação. (BRASIL, 2016).

É importante elucidar alguns dados da região para perceber o quão relevante é o debate sobre as políticas de gestão territorial e ambiental neste contexto. Grande parte da população indígena no Nordeste - cerca de $40 \%$ do total de índios que ali habitam, ou 93.400 pessoas $^{3}$-, reside no semiárido ${ }^{4}$. Segundo os dados do IBGE, a Região Nordeste do Brasil tem a segunda população mais numerosa do país em termos de quantidade de indígenas, contando com um total de 232.739 pessoas. O estado de Pernambuco - no qual se desenvolveram as experiências tratadas aqui -, por sua vez, conta com uma população de 60.995 mil indígenas (IBGE, 2010), sendo o terceiro estado com mais indígenas do país, atrás apenas do Amazonas e Mato Grosso do Sul. 
Essa significativa presença tanto no semiárido, quando em Pernambuco, podem ser conferidas no mapa a seguir. Observem a região semiárida destacada em polígono azul e a concentração de municípios com significativa presença indígena na fronteira entre os estados de Pernambuco e Bahia.

Figura 2 - População Indígena no Semiárido

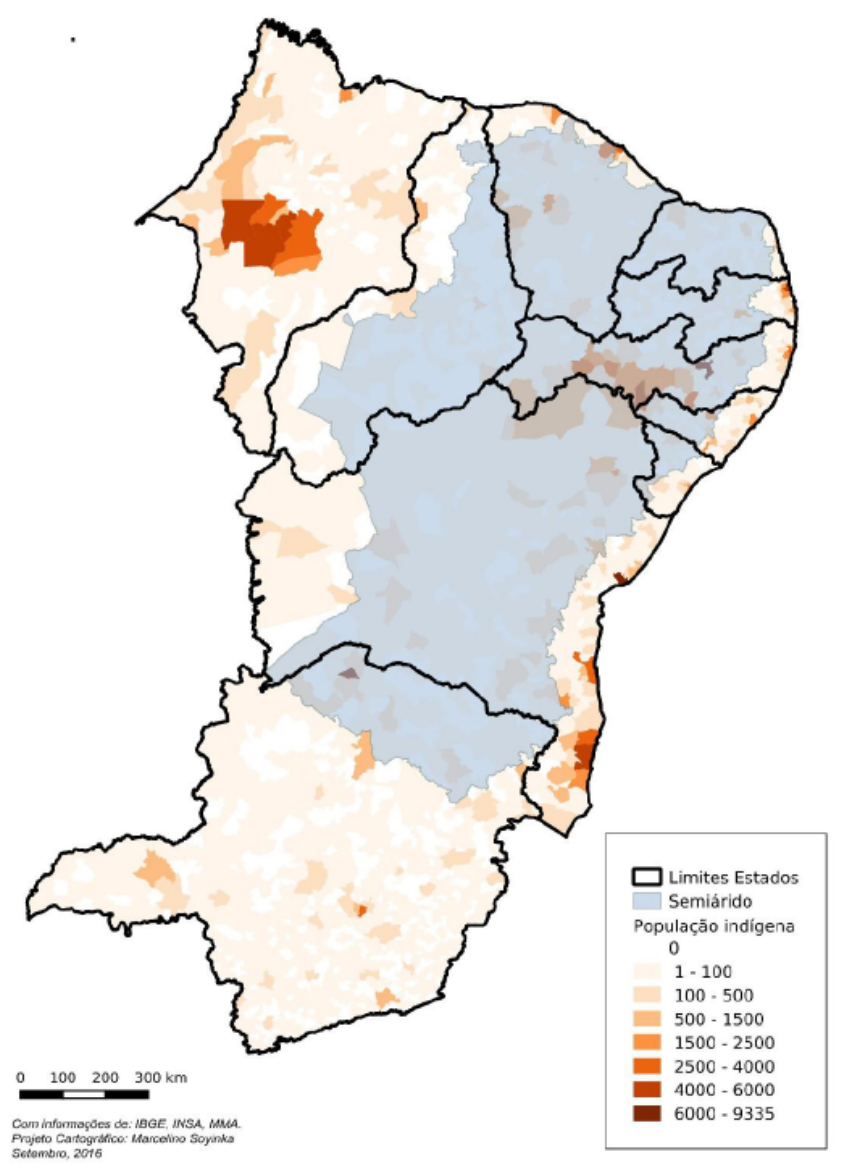

O semiárido se caracteriza por uma combinação entre regime irregular de chuvas, alto grau de incidência solar e por ocorrência frequentes de secas, um dos principais desafios para as populações aí residentes é o acesso a fontes de água que garantam sua sobrevivência, bem como a viabilidade de suas atividades produtivas. No caso dos povos indígenas, esses processos são ainda agravados pela questão fundiária, uma vez que suas terras, quando demarcadas, representam apenas uma fração de seu território tradicional, esbulhado desde os tempos coloniais. Consequentemente, as áreas que restaram a esses povos são em sua maioria distantes das localidades mais férteis à agricultura e das melhores fontes de água, via de regra, regiões incorporadas às grandes propriedades privadas de terra.

Na mesa de abertura do Seminário Pensando Gestão Ambiental e Territorial com Povos Indígenas no Nordeste, realizado em Paulo Afonso/BA, Uiton Tuxá - ex-coordenador da Articulação dos Povos e Organizações Indígenas do Nordeste Minas Gerais e Espírito Santo (APOINME) -, lembrou que foi necessário que a organização colocasse na pauta de interlocução com o Estado a questão da gestão territorial na caatinga para que fosse possível direcionar ações para a região no contexto de projetos pilotos da PNGATI. (ANAÍ, 2015). 
É nesse contexto de mobilização dos indígenas para o direcionamento de projetos pilotos da PNGATI para a região que são desenvolvidos os projetos que refletimos neste artigo.

\section{TECENDO PLANOS: ARRANJOS INSTITUCIONAIS E PARTICIPAÇÃO INDÍGENA NA IDEALIZAÇÃO DOS PROJETOS}

Como mencionado na introdução deste artigo, ambos projetos foram desenvolvidos no âmbito inicial de implementação da PNGATI no Nordeste. Entretanto, apesar de terem sido realizados em anos consecutivos e praticamente com a mesma equipe técnica, foram resultado de processos distintos, conforme descrevemos a seguir.

Em relação ao primeiro deles (cronologicamente falando), desenvolvido junto ao povo indígena Pankararu de Entre Serras, é importante mencionar que o mesmo estava inserido no contexto das ações de um projeto maior, o Projeto Gestão Ambiental e Territorial Indígena $(\mathrm{GATI})^{5}$. Conforme o próprio nome intitula, o mesmo visou desenvolver ações voltadas para a gestão dos territórios indígenas, para tanto trabalhou com trinta e duas TIs em todo o Brasil entre os anos de 2010 e 2016.

Mencionamos isso para apontar que no processo de seleção das TIs de referência - que foi feito em encontros em parceria com as organizações do movimento indígenas em cada região (APIB, 2016) - a TI Entre Serras foi uma das escolhidas em função da uma pauta muito clara: a escassez do caroá

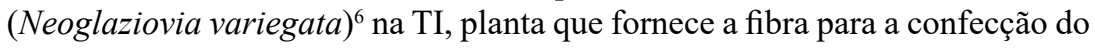
praiá, traje do principal ritual deste o povo.

Uma das ações do Gati nas TIs de referência era a realização de projetos locais que visavam promover diagnósticos colaborativos focados no mapeamento territorial voltado para a elaboração de PGTAs. Neste contexto a APOINME indicou a Associação Nacional de Ação Indigenista (ANAÍ) - organização não-governamental que atua na região há mais de três décadas - para o desenvolvimento de tal projeto no contexto de sua área de abrangência, o Nordeste.

É nessa ocasião que a organização indigenista monta a equipe técnica ${ }^{7}$ que somos convidados para trabalhar, e na qual atuamos entre os anos de 2014 e 2015, junto às comunidades das TIs Caiçara/Ilha de São Pedro (Sergipe) e Entre Serras (Pernambuco). Aqui trataremos apenas da segunda.

O segundo projeto teve o mesmo foco do anterior, porém, teve um processo de articulação distinto. Ainda no período de desenvolvimento da ação junto aos Pankararu foi lançado o edital Projeto BRA 13/019: Implementação da Política Nacional de Gestão Territorial e Ambiental de Terras Indígenas, que visava selecionar "entidades para apoiar a elaboração de etapas ou da totalidade de Planos de Gestão Territorial e Ambiental (PGTAs) em Terras Indígenas localizadas total ou parcialmente nos biomas Caatinga e Cerrado".

É nesse contexto que surge a ideia de desenvolver o mesmo tipo de ação junto ao povo indígena Kapinawá, visto que membros da equipe técnica tinham ações indigenistas orgânicas junto a este povo de longa data, a saber: a atuação do antropólogo José Augusto Laranjeiras desde o início dos anos de 1980, que teve participação nos trâmites para a regularização do território, bem 
como em ações desenvolvidas pela Anaí; e a atuação da também antropóloga Lara Erendira de Andadre, desde o ano de 2011, atuando principalmente em processos de formação dos professores/as indígenas e no desenvolvimento da pesquisa de mestrado (2012-2014) e doutorado (2016-atual).

A proposta foi elaborada e debatida junto ao cacique daquele povo, Robério Maia, e teve como tema central a regularização de parte do território que ainda não tem medidas administrativas tomadas nesse sentido. Para a proposição do projeto foi articulada a ONG Centro de Cultura Luiz Freire (CCLF), que atua desde os anos de 1990 junto aos povos indígenas em Pernambuco, principalmente na temática da educação escolar indígenas e mulheres indígenas.

Achamos importante delinear como o processo de articulação para a elaboração e desenvolvimento do projeto foi feito em cada caso pois isso teve reflexo direto na forma de execução, participação indígena, bem como no resultado de cada um deles.

\section{MAPEAR NÃO É PRODUZIR MAPAS: REFLEXÕES SOBRE NOSSAS CARTOPRÁTICAS}

No texto "Jornada ao longo de um caminho de vida..." Ingold (2005) nos lembra que mapear é mais do que desenhar um mapa, “ 'mapear' e 'elaborar um mapa', segundo Denis Wood, "não significam a mesma coisa (WOOD, 1992, p. 32). Para ele, a diferença é parecida àquela entre falar e escrever" (WOOD, 1992, p. 92).

Gostaríamos de reiterar essa perspectiva do autor para sublinhar nosso entendimento da possibilidade que a prática do mapeamento não seja utilizada como uma ferramenta de controle do Estado sobre os povos indígenas, mas sim uma prática que localiza pessoas e atividades em "ontologias espacializadas", uma cartoprática, como bem destaca Almeida (2012) ao diferenciar cartografia e cartopráticas:

Respeito essa distinção, e se quiserem podemos então distinguir a cartografias e cartopráticas, sendo estas últimas as atividades que localizam pessoas e atividades em ontologias espacializadas. A cartografia no sentido científico-estatal indica a pretensão de situar pessoas e coisas em um espaço único e convencionalizado pela ontologia cartográfica onde escala, projeções e legendas são padronizadas. [...] Em suma, a Antropologia ensina que todos nós somos receptores de GPS e todos nós utilizamos de SIGs embutidos em nossos corpos e mentes. Há, portanto, cartopráticas que são ciências populares associadas a múltiplas ontologias, e que não se confundem nem devem ser invisibilizadas pela ontografia universal que implanta cada fragmento da experiência num geoide único. Corpos são GPSs portáteis e embutem SIG tradicionais; mas nada impede que cartografias tradicionais - esses híbridos da experiência espacial com a representação gráfica - possam canibalizar essas tecnologias a seu serviço, de forma a dialogar com as ontografias universais. (ALMEIDA, 2012, p. 15-16).

É nesta perspectiva de cartopráticas que acreditamos, e que só é possível a partir de processos de mapeamento que pratiquem a ideia de participação de forma radical, levando a cabo o entendimento de que nosso trabalho é um lócus de encontro de conhecimentos. Como menciona Cardoso (2014), "é interessante observar os contemporâneos esforços de etnomapeamento para/com/ dos povos indígenas como uma experiência intercientífica que se realiza no 
cruzamento de múltiplos regimes de conhecimento, notadamente os das ciências e os tradicionais. (TURNBULL, 2003; CARDOSO, 2014, p. 2).

Nossas cartopráticas envolveram uma série de ações: caminhadas, oficinas, conversas, textos, desenhos diversos e desenhos de mapas, usos de equipamentos como câmeras fotográficas e GPSs, entre outras. A seguir, refletiremos principalmente sobre as formas de atuação indígena, como isso influenciou na condução das atividades, assim como nos resultados dos mapeamentos.

\section{SOBRE A PARTICIPAÇÃO INDÍGENA}

Em ambos casos, o trabalho abarcou as três etapas previstas para os processos de construção dos PGTAs: sensibilização, diagnóstico e planejamento. (FUNAI, 2013, p.9). Importante frisar que estas etapas, ou ciclos do processo de construção dos PGTAs, apesar de distintas ocorrem de maneira não necessariamente linear e exclusiva ao longo do processo. (LITTLE, 2006). Deste modo, a pesquisa bibliográfica ocorreu durante todo o período, ao mesmo tempo em que as oficinas das etapas de diagnóstico também funcionam como momentos de sensibilização, na medida em que os participantes foram se familiarizando e apropriando da proposta com o decorrer da execução dos trabalhos. Importante ressaltar também que, tal qual diversos processos (MACIEL, 2015), as etapas de planejamento, que requerem um tempo maior de reflexão, discussão e construção de acordos coletivos, não foi aprofundada nestes processos, por limitações de tempo e outros pontos que são detalhados a seguir.

No diagnóstico foram realizadas atividades de levantamento bibliográfico, oficinas participativas para elaboração de mapas, calendários produtivos, listagem de informações diversas, caminhadas guiadas para mapear e reconhecer o território, conversas com interlocutores-chave, etc.

Para todo o funcionamento de ambos os projetos, seja para a realização de oficinas ou caminhadas no território, agrupamos - a partir do diálogo com os indígenas - as atividades em conjuntos de aldeias de acordo com lógicas locais de afiliação política e fatores territoriais.

As atividades em Entre Serras ocorreram entre junho de 2014 e janeiro de 2015 e contaram com a participação de mais de sessenta pessoas de dezessete aldeias, que eram tanto da TI Entre Serras, quanto da TI Pankararu. Em Kapinawá foi possível desenvolver as ações num período mais extenso, entre junho de 2015 e fim de 2016, neste contexto os trabalhos envolveram mais de duzentas indígenas, das mais de vinte e cinco aldeias, com participação massiva dos professores indígenas.

Aqui vale destacar que a TI Pankararu é contígua à Entre Serras, e constitui-se um mesmo grupo que, apesar dos faccionalismos, compartilha história e usos do território. A partir desta constatação criou-se o entendimento da equipe técnica e dos indígenas, embora inicialmente a proposta fosse trabalhar apenas em um dos territórios, não faria sentido fazê-lo sem dialogar com os Pankararu da TI homônima. Esta decisão teve consequências operacionais que influenciaram nos processos e resultados, uma vez que toda estrutura de equipe e logística pensada para um processo teve que ser praticamente duplicada, sem adição orçamentária.

Os contextos de articulação dos projetos narrados acima, bem como os arranjos locais para realização dos mesmos resultaram em formas distintas de engajamentos dos indígenas e de envolvimento da equipe técnica com a realidade local. Isto por sua vez teve implicações diretas nos resultados e des- 
dobramentos posteriores. Em ambos os casos as equipes de trabalho foram formadas por indígenas e indigenistas. No caso de Entre Serras, os indígenas que participaram mais ativamente ao longo do processo tinham formação especializada de cineasta e geógrafa, neste acabaram por não seguir a lógica da distribuição territorial das oficinas; no caso Kapinawá contamos com quatorze pessoas (principalmente professores/as), que se dividiram em três núcleos.

No caso de Entre Serras, lideranças que participam ativamente na organização política regional, a Apoinme, tiveram papel fundamental na escolha dessa área para o projeto GATI. Esta articulação em nível mais macro resultou na abertura de diálogo com a organização executora do projeto, a Anaí. Diferente do caso Kapinawá, a Anaí não tinha histórico de atuação local nestas TIs. Outra informação relevante é que a equipe técnica foi reunida especificamente para este fim em função de suas qualificações individuais e experiências em suas áreas de especialidade e junto a povos indígenas. Dessa forma, pode-se dizer que parte do processo consistiu em realizar esta sensibilização de mão dupla: da equipe entre si, da equipe junto aos indígenas e dos indígenas residentes nas aldeias, muitas vezes afastados das discussões travadas junto às suas organizações formais, para a relevância da discussão desta chamada "gestão territorial".

Essas particularidades, aliadas ao curto período para execução do processo, e à reorganização do mesmo em face das características do povo e do território citadas anteriormente, resultou que na TI Entre Serras, o principal "resultado" da participação indígena na equipe foi o registro audiovisual, que resultou em vídeo com conteúdo semelhante ao do relatório, conforme elucidaremos a seguir.

Nas oficinas, por sua vez, foram envolvidos diretamente um grupo reduzido de pessoas, resultado tanto de processos internos em um contexto de conflitos, quanto do curto tempo de trabalho da equipe. O breve tempo do projeto não possibilitou aprofundar o diálogo e a reflexão da proposta por um número maior de indígenas. Dessa forma, a proposta seguiu um rumo mais de diagnóstico propriamente dito, uma vez que a discussão das questões levantadas e a tomada de decisão sobre planos de ações a seguir demandaria um tempo para disseminação destas discussões a um maior número de participantes de suas aldeias.

Por outro lado, consolidou um grupo de indígenas mobilizados no tema da gestão que, no ano seguinte, apresentaram através da própria associação indígena um projeto no edital já mencionado de Implementação da Política Nacional de Gestão Territorial e Ambiental de Terras Indígenas.

No caso Kapinawá, conforme citado, havia um maior envolvimento prévio entre parte da equipe técnica. Vale mencionar ainda que concomitantemente às ações do PGTA, uma das técnicas também coordenava projeto ${ }^{9}$ que envolvia os professores indígenas kapinawá na pesquisa e elaboração de um livro de autoria indígena sobre seu contexto. Este arranjo permitiu que tanto os professores indígenas, quanto equipe técnica vislumbrassem potencialidades no diálogo entre as ações dos dois projetos, o que resultou num envolvimento mais disseminado de participantes indígenas diretamente no processo de construção do mapeamento e PGTA.

Neste contexto as aldeias do território foram agrupadas dividindo-o em três núcleos de acordo com a organização social e territorial local: norte, centro e oeste. Como mencionado, as oficinas contaram com um grande quantitativo de pessoas, e a equipe local de pesquisadores/as indígenas que fez parte da equipe técnica teve catorze pessoas. 
Após um primeiro momento de oficinas em que se discutiu coletivamente os principais temas de relevância a serem aprofundados também foram indicados os pesquisadores indígenas de cada núcleo, a maioria professores indígenas.

Em um momento seguinte foi elaborado um roteiro de pesquisa em oficina específica com tais pesquisadores. Essa pesquisa resultou num conjunto de dados respondendo ao roteiro, fotografias, vídeos de relatos e coordenadas de GPS dos locais de interesse, tudo produzido pelos pesquisadores indígenas.

O principal momento de produção destas informações foi realizado entre as estadias em campo da equipe do CCLF. Por este contexto distinto, ao contrário da ação em Pankararu aqui os pesquisadores/as indígenas tiveram formação para o uso de ferramentas técnicas específicas de georreferenciamento, como receptores GPS. Assim, entre as estadias da equipe técnica do projeto, os indígenas registraram centenas de pontos de GPS.

O engajamento de professores, e a realização do projeto do livro kapinawá mencionado proporcionou que os resultados das pesquisas do etnomapeamento fossem incorporados à rotina escolar, e, ao fim dados para a pesquisa dos professores indígenas para o seu livro.

\section{SOBRE A CONSTRUÇÃO DOS MAPAS}

Um dos frutos do mapeamento, ainda que não o único, como comumente se espera, foram os mapas propriamente ditos. A maioria deles foram resultados das temáticas que surgiram ao longo das discussões nas oficinas, ou que tinham a ver com os principais fatores motivadores que levaram aos indígenas encamparem estes projetos, sejam eles: a questão do caroá, entre os Pankararu; e a área não regularizada, entre os Kapinawá. Abaixo agrupamos os mapas por algumas categorias temáticas que analisaremos em seguida.

\begin{tabular}{|c|c|c|}
\hline TEMAS & $\begin{array}{l}\text { ENTRE SERRAS } \\
\text { PANKARARU }\end{array}$ & KAPINAWÁ \\
\hline $\begin{array}{l}\text { Contextuali- } \\
\text { zação }\end{array}$ & $\begin{array}{l}\text { Mapa } 3 \text { - Pontas de } \\
\text { Rama Pankararu } \\
\text { Mapa } 4-\text { Fluxos de } \\
\text { povoamento } \\
\text { Mapa } 6 \text { - Entre Serras } \\
\text { e Pankararu no con- } \\
\text { texto regional }\end{array}$ & $\begin{array}{l}\text { Mapa } 1 \text { - População indígena no se- } \\
\text { miárido - População indígena por } \\
\text { Mapa 2 - Poperán } \\
\text { município em Pernambuco } \\
\text { Mapa } 5 \text { - Contexto Regional: terras } \\
\text { indigenas próximas - PE } \\
\text { Mapa 6 - Polígono estimado da pro- } \\
\text { priedade "macaco dos índios" }\end{array}$ \\
\hline $\begin{array}{l}\text { Políticas } \\
\text { públicas }\end{array}$ & $\begin{array}{l}\text { Mapa 1 - População } \\
\text { por aldeias e divisão } \\
\text { municipal } \\
\text { Mapa } 2-\text { Distribuição } \\
\text { das residências nas } \\
\text { terras indígenas } \\
\text { Mapa 16-Rodoviá- } \\
\text { rio - distâncias }\end{array}$ & $\begin{array}{l}\text { Mapa } 3 \text { - Aldeias Kapinawá } \\
\text { Mapa } 4 \text { - Políticas públicas e infra- } \\
\text { estrutura }\end{array}$ \\
\hline Água & $\begin{array}{l}\text { Mapa 10 - Imagem } \\
\text { de satélite setembro } \\
1984 \text { (seca) } \\
\text { Mapa 11) Imagem } \\
\text { de satélite maio } 1994 \\
\text { (estação chuvosa) } \\
\text { Mapa } 12 \text { - Imagem de } \\
\text { satelitite abril 1986 (es- } \\
\text { tação chuvosa) } \\
\text { Mapa 13 - Imagem } \\
\text { de satélite julho 2013 } \\
\text { (estação chuvosa) }\end{array}$ & $\begin{array}{l}\text { Mapa } 15 \text { - Fontes de água - norte } \\
\text { Mapa } 16 \text { - Fontes de água - centro } \\
\text { Mapa } 17 \text { - Fontes de água - sul }\end{array}$ \\
\hline
\end{tabular}




\begin{tabular}{|c|c|c|}
\hline $\begin{array}{l}\text { Cobertura } \\
\text { do solo }\end{array}$ & $\begin{array}{l}\text { Mapa } 5 \text { - Destaque: } \\
\text { TI Entre Serras Re- } \\
\text { gião das aldeias Novo } \\
\text { Mundo, Lagoinha e } \\
\text { Barriguda } \\
\text { Mapa } 7 \text { - Vegetação } \\
\text { nas terras indígenas } \\
\text { Mapa } 8 \text { - Formações } \\
\text { de vegetação nas ter- } \\
\text { ras indígenas e ocor- } \\
\text { rência de croá } \\
\text { Mapa } 9 \text { - Mudancas } \\
\text { na vegetação 1986- } \\
\text { 2013 } \\
\text { Mapa } 14 \text { - Distri- } \\
\text { buição do umbu e do } \\
\text { murici segundo os } \\
\text { Pankararu }\end{array}$ & $\begin{array}{l}\text { Mapa } 9 \text { - Cobertura do solo } \\
\text { Mapa } 10 \text { - VEGETAÇA área sul } \\
\text { Mapa } 11 \text { - VEGETACAO área centro } \\
\text { Mapa } 12 \text { - VEGETACAAO área leste } \\
\text { Mapa } 13 \text { - VEGETAÇA área norte } \\
\text { Mapa } 14 \text { - VEGETAÇÃO área oeste }\end{array}$ \\
\hline Tradição & ----- & $\begin{array}{l}\text { Mapa } 18 \text { - Tradição kapinawá } \\
\text { Mapa } 19 \text { - Furnas e letreiros } \\
\text { Mapa } 22 \text { - Tradição Ibimirim }\end{array}$ \\
\hline $\begin{array}{l}\text { Conflitos } \\
\text { e situação } \\
\text { territorial }\end{array}$ & $\begin{array}{l}\text { Mapa } 17 \text { - Destaque: } \\
\text { TI Entre Serras, pro- } \\
\text { ximidades da área ur- } \\
\text { bana de Tacaratu: li- } \\
\text { xão e outras pressões } \\
\text { Mapa } 15 \text { - Ameaças e } \\
\text { posses não pankararu } \\
\text { Mapa } 18 \text { - Ameaças } \\
\text { ambientais de escala } \\
\text { regional às terras in- } \\
\text { digenas }\end{array}$ & $\begin{array}{l}\text { Mapa } 7 \text { - TI Sobreposição } \\
\text { Mapa } 8 \text { - Area nova- desenhado } \\
\text { Mapa } 20 \text { - Aldeias de Ibimirim } \\
\text { Mapa } 21 \text { - Vegetação de Ibimirim }\end{array}$ \\
\hline
\end{tabular}

Conforme pode ser conferido acima agrupamos os mapas produzidos em categorias que nos possibilitassem refletir sobre alguns aspectos, sejam elas: mapas de contextualização, políticas públicas, água, ambiental e produtivo, tradição, conflitos e situação territorial. É importante mencionar que esta classificação é um artifício analítico, não deve ser vista de forma monolítica, pois, como poderá ser percebido, vários dos mapas poderiam estar encaixados em mais de uma delas.

Outro aspecto importante a ser mencionado é que, ao optar por listar apenas os títulos, uma série de outras informações que estão contidas nos mapas - e nos processos que resultaram em sua construção - não são evidenciadas, o que é de certa maneira suprido pelas análises que seguem. Tais mapas podem ser apreendidos de forma mais completa ao acessar os livros publicados, falaremos sobre eles na sessão seguinte.

Vamos aos mapas. Como a tabela acima enumera foram produzidos algumas dezenas deles. No caso Pankararu, foram dezoito, em Kapinawá, vinte e dois. Além da variedade temática, vale destacar a diversidade de formatos nos resultados finais - sem contar com os mapas que foram produzidos ao longo do processo para subsidiar a discussão, mas que não entraram na publicação final dos projetos. Dispomos de mapas que contam com informações unicamente produzidas através de programas computacionais específicos de Sistemas de Informação Geográfica - SIG; unicamente desenhados a mão (mapa mental ou livre); e ainda aqueles produzidos com técnicas mistas, com mapas mentais produzidos sobre uma base cartográfica georreferenciada produzida em SIG (com desenhos com lápis de colorir sobre polígonos e pontos plotados em cartolinas em fundo branco).

Inicialmente há um conjunto de mapas que foram produzidos para contextualizar os povos em suas respectivas regiões em aspectos históricos, políticos e ambientais. A seguir foram apresentados mapas produzidos a partir de diálogos bem específicos em relação às potencialidades dos mesmos como instrumentos de diálogo com o Estado na demanda pela efetivação de políticas 
públicas. Foram tratadas principalmente as políticas de educação e saúde específicas para os povos indígenas, e ainda por infraestrutura das estradas de acesso às comunidades, que são de responsabilidade dos municípios. Destacamos dois exemplos, relativos ao interesse dos indígenas em projetar a distância entre as aldeias, entrecruzando com informações das divisões municipais, por dois motivos: (1) o primeiro deles foi construído a partir da ideia dos indígenas de utilizá-lo como um instrumento de diálogo para a regularização dos transportes escolares, e consequentemente a situação dos motoristas indígenas, possibilitando o cálculo de quilômetros rodados pelos mesmos no transporte de crianças e adolescentes de suas aldeias para as escolas indígenas; (2) outro motivo foi identificar qual a prefeitura responsável pela manutenção das estradas de barro que cortam as TIs, tendo em vista que cada uma das terras trabalhadas aqui abrangem áreas de três municípios distintos do estado de Pernambuco.

Um terceiro conjunto de mapas foram elaborados a partir de uma questão muito cara quando se trata de gestão de um território no semiárido: o acesso à água. Citamos três exemplos: (1) Em ambos os casos foi tratada a diminuição do fluxo de água das nascentes resultado do desmatamento da região ao seu redor; (2) Entre os Kapinawá outro aspecto foi o conflito com a Secretaria Espacial de Saúde Indígena (Sesai) em função de poços artesianos para o abastecimento de algumas aldeias. Em algumas os poços ainda não foram perfurados e em outras há o mal funcionamento de bombas que impedem o devido acesso a tal recurso. Os Pankararu, por sua vez, indagaram o cercamento e privatização das margens do Rio São Francisco, que impede os indígenas, que tem sua TI há menos de 4 quilômetros do curso do rio, ter acesso ao mesmo para usos tradicionais, ou mesmo para a pesca.

Figura 3 - Recorte do mapa produzido durante oficina na TI Entre Serras

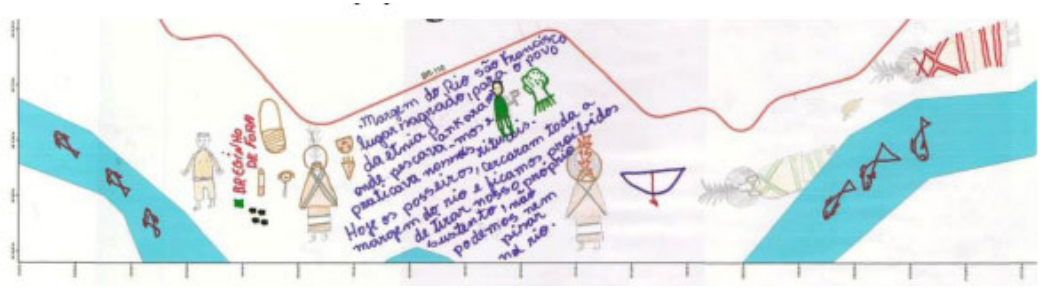

Ainda nessa (3) temática há uma série de quatro mapas que apresentam imagem de satélite das TIs Pankararu e Entre Serras em anos diferentes: setembro 1984 (seca), abril 1986 (estação chuvosa), maio 1994 (estação chuvosa) e julho 2013 (estação chuvosa). A opção foi por apresentar as imagens em quatro anos distintos, em meses diversos, ao longo de quase 30 anos. A comparação entre os quatro mapas nos permite ver as alterações: no ambiente, as distinções entre a estação chuvosa e da seca; bem como o recorte temporal permite visualizar a área alagado pelo lago artificial formado pelo reservatório da Usina Hidrelétrica de Itaparica (atualmente denominada Luiz Gonzaga-Itaparica), em fins dos anos 80 . Vale mencionar que a construção da hidrelétrica e consequente criação do lago teve fortes impactos na vida cotidiana dos Pankararu: além dos desequilíbrios ambientais e sociais causados pela magnitude da obra e volume de pessoas atraídas à região em decorrência da mesma, no âmbito religioso a cachoeira de Itaparica, local do represamento, era um importante espaço ritual para este povo e para outros da região.

Os mapas de cobertura do solo por sua vez foram os mais numerosos. No caso Kapinawá foi feito um mapa geral e os outros cinco foram recortes que trazem uma aproximação em escala maior deste primeiro, para maior detalhamento. No mapeamento dos Pankararu, ao contrário do que imaginávamos num primeiro momento em função do caroá ter sido o fator mobilizador inicial, esse não foi o tema "central" do diagnóstico, mas coadjuvou com os demais temas 
aqui apresentados. A principal constatação com esses mapas foi a visualização da grande área de caatinga preservada no interior das TIs, somando em ambas (Pankararu e Entre Serras) mais de 50\% de suas áreas compostas ainda de cobertura da mata nativa.

Em relação aos mapas que tratam do que chamamos de tradição, há um vazio intencional na tabela. Enquanto os pesquisadores/as kapinawá coletaram mais de 70 pontos com os seus GPS, entre eles marcos de cemitérios, capelas, árvores, serras, pedras, sítios arqueológicos, etc.Os Pankararu definiram que não mapeariam tal elemento, pois, como disseram, "o povo daqui já sabe onde fica". Afirmando que isso pertence ao âmbito do segredo ritual do grupo.

Figura 4 - Área Nova Kapinawá

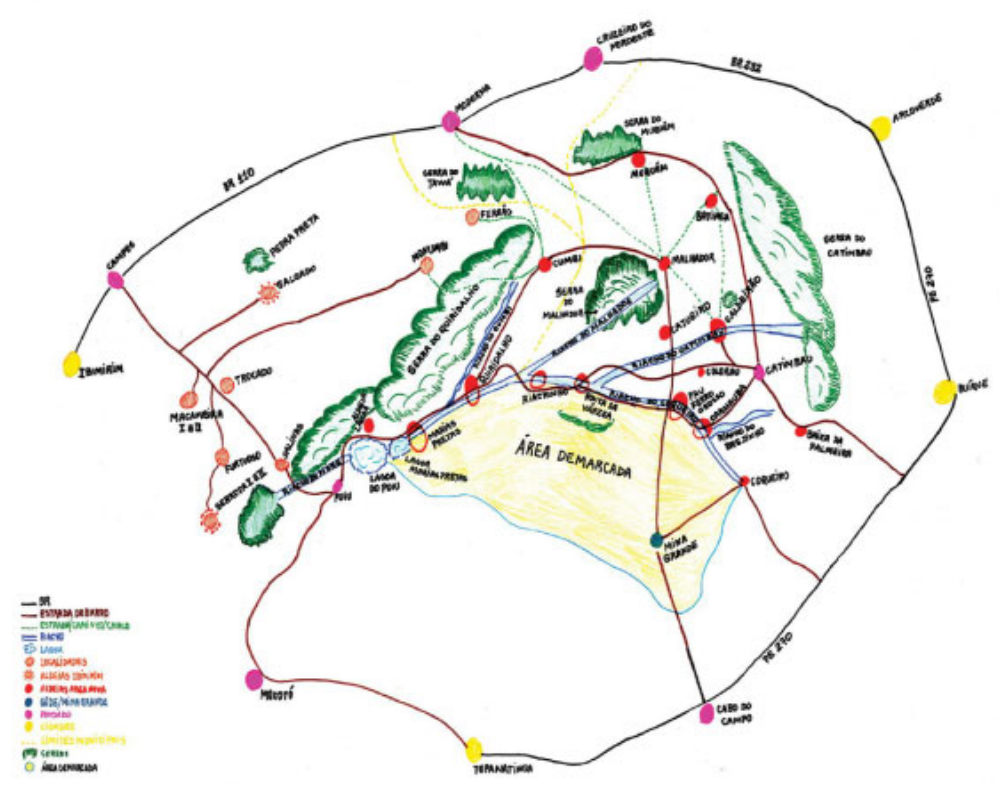

Figura 5 - Tradição Kapinawá

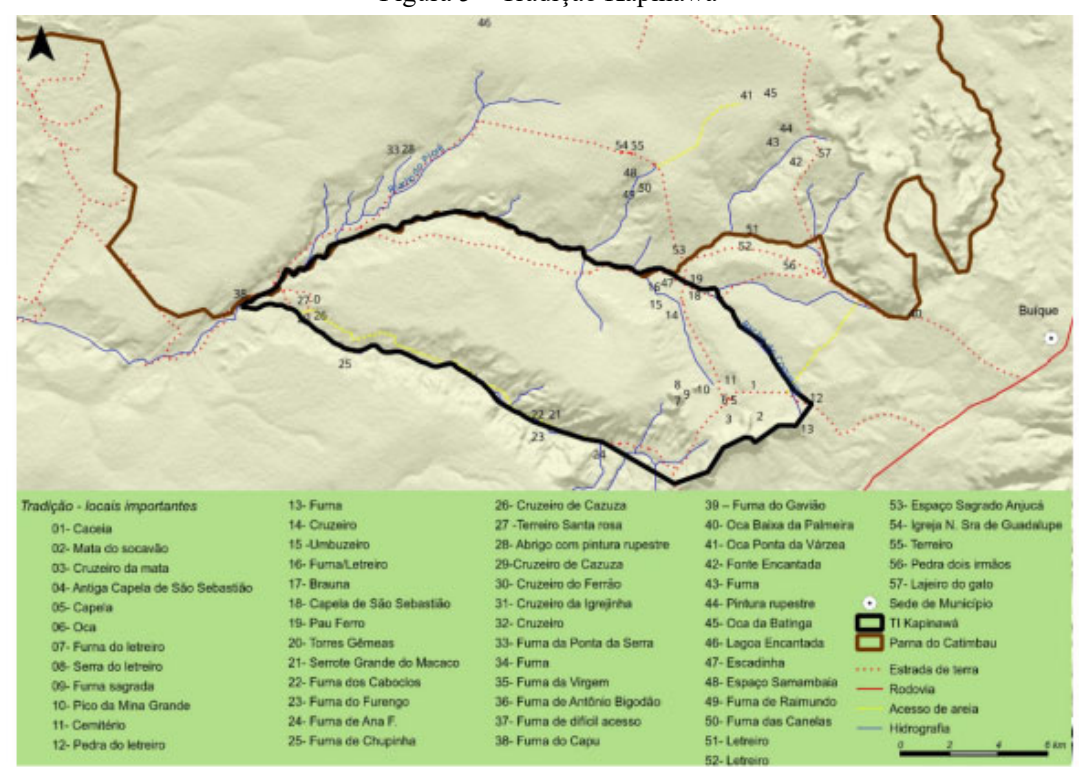


Por fim, agrupamos uma série de mapas no que chamamos de conflitos e situação territorial. Esse tema foi, sem dúvidas, o que mais mobilizou os participantes dos processos de mapeamento. No caso pankararu destacam-se os temas dos mapas: os grandes projetos de desenvolvimento, um lixão na TI, presença de posseiros no interior das TIs demarcadas, e a falta de acesso ao Rio São Francisco. Em Kapinawá, destacamos os mapas que versam sobre a área de seu território que não foi compreendida pela demarcação e que teve uma unidade de conservação (Parque Nacional do Catimbau) criada em sobreposição a essa região.

É interessante observar este aspecto pois, em ambos os casos, os projetos de debate sobre a gestão ambiental e territorial, há o entendimento do Estado, que tais projetos devem ser trabalhados com aqueles povos que já passaram pelo processo de regularização fundiária e têm as TIs homologadas (APIB, 2016). Acontece que as terras indígenas no Nordeste são deveras diminutas, quando comparadas com aquelas demarcadas na região Centro-Oeste ou no Norte. As TIs Entre Serras e Pankararu têm uma extensão respectivamente de 7.750 ha e 8.100 ha. A TI Kapinawá, por sua vez, conta com 12.403 ha. Levando em consideração os grandes contingentes populacionais da região citados anteriormente e as pequenas dimensões de seus territórios, percebe-se por que os grandes eixos mobilizadores das discussões foram exatamente as partes dos territórios que não foram contempladas nos processos de regularização fundiária, bem como os respectivos conflitos decorrentes.

\section{OUTRAS FORMAS DE APRESENTAR NOSSAS CARTOPRÁTICAS}

Os resultados de ambas experiências foram organizados em formato de publicações. No caso Pankararu, ela contou com um livro e um filme relatando a experiência. Para a produção final do livro, o texto e os mapas de diagnóstico do mapeamento realizados pela equipe técnica da Anaí foram trabalhados em formato de oficinas com um conjunto de professores indígenas de Entre Serras, que tanto refletiram quais seriam os trechos interessantes a serem publicados, quanto produziram novos textos e mapas: Etnomapeamento da Terra Indigena Entre Serras Pankararu (ANDRADE, DANTAS; NILSSON, 2016) ${ }^{10}$. O vídeo, por sua vez, foi realizado pelo cineasta indígena Pankararu que registrou todas as etapas do projeto, e produziu o que chamamos de "PGTA em vídeo": Mapeamento Pankararu (Alexandre Santos - Xandão Pankararu) ${ }^{11}$.

A experiência Kapinawá foi publicada no livro: $O$ tempo e a terra: mapeamento o Território Kapinawá (ANDRADE; DANTAS, 2017) ${ }^{12}$. Ainda vale destacar que a pesquisa do mapeamento foi utilizada pelos mais de 150 professores indígenas Kapinawá no livro mencionado ao longo do texto. $\mathrm{O}$ que possibilitou que dados do projeto do PGTA fossem incorporados de forma orgânica nesta publicação, e, mais do que isso, que uma pesquisa retroalimentasse a outra. O livro intitula-se: Kapinawá - território, memórias e saberes (Professores/as indígenas Kapinawá, 2016) ${ }^{13}$.

\section{CONSIDERAÇÕES FINAIS}

No início deste texto nos referimos aos mapas como um instrumento de guerra, que tem sido, por séculos, ferramenta de dominação. Contudo, ao longo das últimas décadas ele também foi apropriado pelos indígenas nos processos de mobilização política para uso em favor de suas causas. Apresentamos 
como esse processo de mobilização política possibilitou, inclusive, a inserção do mapeamento participativo como uma ferramenta de implementação de política pública. Voltamos aqui para a questão que colocamos na primeira seção deste texto: os mapeamentos participativos, agora incorporados como ferramenta de política pública, correm risco de perder seu caráter de autonomia e de "contra-ataque"?

Bom, o certo é que não temos uma resposta monolítica a tal questão. Ao longo do texto tentamos, a partir das duas experiências narradas, mostrar as diversas facetas que o processo de mapeamento pode tomar. Assim como sugeriu Almeida (2012), os Kapinawá e os Pankararu fizeram um processo de "canibalizar essas tecnologias a seu serviço, de forma a dialogar com as ontografias universais". O mesmo já havia observado Cardoso et al (2017) ao falar do caso Potiguara:

[...] assim como outros mapas produzidos na região ao longo da história do contato interétnico, o processo do etnomapeamento foi reorientado pelos Potiguara, num processo de "cartografofagia", em que as técnicas planejadas de "cima" - isto é, pelo órgão indigenista — foram "digeridas" e tratadas como "mapas indígenas" para fins, principalmente, de luta territorial, num processo cosmopolítico em que nenhuma parte envolvida detinha o controle da narrativa.(CARDOSO, 2017, p. 73).

Uma coisa é certa, ter o mapeamento participativo como uma metodologia estabelecida como parte de um decreto de lei, é, sem dúvidas, um grande passo, especialmente quando isso vem como fruto de demandas colocadas em pauta pelo próprio movimento indígena (APIB, 2016). Mas é preciso que esta perspectiva de deixar-nos comer seja uma prática cotidiana, de outra forma, os mapas podem rapidamente voltar a ter sua função de dominação, agora travestido com a feição de participação. Sublinhamos isso particularmente nestes contextos de tradução das práticas da gestão territorial e ambiental indígena sobre seus territórios, é preciso não perder de vista que

As lógicas de governança não devem ser reduzidas/consumida pela lógica da gestão administrativa. [...] os planos de gestão ambiental e territorial não podem ser convertidos em novos instrumentos de as sujeitamento, ao contrário, devem fortalecer a governança dos povos indígenas em suas terras de ocupação tradicional, favorecendo diálogos através de canais de expressão de categorias endógenas e não da imposição de categorias exógenas por meio de metodologias indutivas. (JACKUBAZKO, 2012, p. 49-50).

Deixar-nos devorar e tais metodologias serem 'digeridas' e transformadas pelos povos indígenas, retrabalhando-as para delas surgirem mapas indígenas, bem podem servir como barricadas aos ataques anti-indígenas que se anunciam para os próximos períodos.

\section{NOTAS}

${ }^{1}$ Destacam-se neste sentido o artigo 231, que reconhece aos povos indígenas o direito originário e conceitua o que seriam suas "terras tradicionalmente ocupadas", e o art. 68 das Disposições Constitucionais Transitórias, que trata dos direitos das comunidades quilombolas. Estes dispositivos abrem ensejo ao reconhecimento de territorialidades distintas até então não reconhecidas no aparato legal brasileiro.

2 Disponível em: <http://brasil.gov.br/cidadania-e-justica/2014/07/terras-indigenas-tem-menor-indice-de-desmatamento-na-amazonia-legal $>$. Dados do censo IBGE 2010. Disponível em:<http://indigenas.ibge.gov.br>. Informação calculada também a 
partir de dados do Instituto Nacional do Semiárido. (SIGSAB, 2016).

${ }^{3}$ Dados do censo IBGE 2010. Disponível em: $<$ http://indigenas.ibge.gov.br $>$. Informação calculada também a partir de dados do Instituto Nacional do Semiárido. (SIGSAB, 2016).

${ }^{4} \mathrm{O}$ semiárido brasileiro engloba áreas do Sertão nordestino e alguns municípios do norte de Minas Gerais, conforme critérios definidos na portaria 89/2005 do Ministério da Integração Nacional.

${ }^{5}$ Conforme descrição em sua página institucional: “O Projeto Gestão Ambiental e Territorial Indígena - GATI tem como objetivo principal o fortalecimento das práticas indígenas de manejo, uso sustentável e conservação dos recursos naturais e a inclusão social dos povos indígenas, consolidando a contribuição das Terras Indígenas como áreas essenciais para conservação da diversidade biológica e cultural nos biomas florestais brasileiros. O Projeto é uma realização conjunta entre o movimento indígena brasileiro, Fundação Nacional do Índio (FUNAI), Ministério do Meio Ambiente (MMA), The Nature Conservancy (TNC), Programa das Nações Unidas para o Desenvolvimento (PNUD) e Fundo Mundial para o Meio Ambiente (GEF-Global Environment Facility)". Disponível em: <http://cggamgati.funai.gov.br/>.

${ }^{6}$ Caroá (Neoglaziovia variegata) é um tipo de bromélia que fornece fibra utilizada tradicionalmente por diversos povos do sertão nordestino. Esta fibra é utilizada em utensílios de uso cotidiano e também na construção de trajes rituais entre os Pankararu, e por esta razão a planta ocupa um lugar de relevância na vida destes.

${ }^{7}$ Além dos autores do presente artigo, a equipe também contou com a participação de Ana Paula Ferreira de Lima (gestora); Avelar Araújo dos Santos Júnior (geógrafo); Maurice Seiji Tomioka Nilsson (geógrafo); bem como de dois indígenas pankararu, Alexandre Santos Pankararu (cineasta) e Cristiane Gomes Julião (geógrafa). A supervisão foi feita por: Isabel Fróes Modercin (bióloga/antropóloga - Projeto GATI) e José Augusto Laranjeiras Sampaio (antropólogo - ANAI).

${ }^{8}$ A equipe técnica do projeto junto aos Kapinawá contou com a participação de Ana Paula Ferreira de Lima (gestora); Lara Erendira Almeida de Andrade (antropóloga), Marcelino Soyinka (biólogo), José Augusto Laranjeiras Sampaio (supervisor técnico/ colaborador Anaí);

${ }^{9} \mathrm{O}$ projeto em questão era financiado pelo edital do Fundo Pernambucano de Apoio a Cultura (FUNCULTURA), da Fundação do Patrimônio Histórico e Artístico de Pernambuco (FUNDARPE).

10 Disponível em: <http://cggamgati.funai.gov.br/files/1714/8776/9858/Etnomapeamento_TI_Entre_Serras_de_Pankararu.pdf $>$.

${ }^{11}$ Disponível em: <https://1drv.ms/b/s!AoiZuL-mnp27g60qJwG4g2kmlR4ezQ>.

${ }_{12}$ Disponível em: <http://cclf.org.br/project/o-tempo-e-a-terra-mapeando-o-territorio-indigena-kapinawa/>.

${ }^{13}$ Disponível em: $<$ http://cclf.org.br/project/kapinawa/>.

\section{REFERÊNCIAS}

ACKUBAZKO, Andreia. Fundamentos e práticas metodológicas presentes na elaboração do Plano de Gestão Territorial Mỹky. In: Jeitos de Fazer - experiências metodológicas para a elaboração de planos de gestão territorial em terras indigenas / Artema Lima, Andreia Fanzeres, Juliana Almeida (organizadoras). Campinas, SP: Curt Nimuendajú, 2012.

ACSELRAD, Henri; COLI, Luis R. Disputas territoriais e disputas cartográficas. In: Cartografias Sociais e Território. Henri Acselrad (Org.). Rio de Janeiro, RJ: UFRJ/IPPUR, 2008. Disponível em: $<$ http://www.ettern.ippur.ufrj. br/central_download.php?hash=467ab838abf48499b7dbb9f41fa3268c\&id=8>. ALMEIDA, Alfredo Wagner Berno. A guerra dos mapas. Belém: Falagola,1994. ALMEIDA, Mauro William Barbosa de. Outros Mapas. Conferência de encerramento no Seminário Outros Mapas: Cartografia e Pesquisa Social . Recife: 
FUNDAJ, 2012. Disponível em: <https://mwba.files.wordpress.com/2010/06/ almeida-2012-outros-mapas-cartografia.pdf $>$.

ANAÍ. Produto 7 - Pensando a Gestão Ambiental e Territorial com povos indigenas na Caatinga. Salvador: Anai, maio 2015.

ANDRADE, Lara E. A. de; DANTAS, Marcelino S. O tempo e a terra: mapeamento o Território Kapinawá. Olinda: CCLF, 2017. Disponível em: <https:// 1drv.ms/f/s!AoiZuL-mnp27g_IukYvq1GwGqgcaQg>.

ANDRADE, Lara E. A. de; DANTAS, Marcelino S.; NILSSON, Maurice T. Etnomapeamento da Terra Indígena Entre Serras Pankararu. Salvador: Anai, 2016. Disponível em: <https://1drv.ms/b/s!AoiZuL-mnp27g60qJwG4g2kml$\mathrm{R} 4 \mathrm{ezQ}>$.

Articulação dos Povos Indígenas do Brasil - APIB. Participação e protagonismo indígena - A experiência do projeto GATI. Brasília, DF: IEB, 2016.

BAVARESCO, Andréia; MENEZES, Marcela. Entendendo a PNGATI: Política Nacional de Gestão Territorial e Ambiental Indígenas. - Brasília: GIZ/Projeto GATI/Funai, 2014.

BRASIL, Caatinga - monitoramento do desmatamento dos biomas brasileiros por satélite - Relatório técnico 2010/2011. MMA/IBAMA, 2016

CARDOSO, T.; PARRA, L.; MORDECIN, I. Mapas em Movimento os (des) caminhos de uma prática cartográfica junto aos potiguara. Espaço Ameríndio, Porto Alegre, v. 11, n. 2, p. 71-111, jul./dez. 2017.

CARDOSO, Thiago Mota; GUIMARÃES, Gabriella (Orgs.). Etnomapeamento das terras Potiguara. Brasília: FUNAI/CGMT/CGETNO/CGGAM, 2012.

CARDOSO, Thiago Mota; PINHEIRO, Maíra Bueno (Orgs.). Aragwaksã: Plano de Gestão Territorial do povo Pataxó de Barra Velha e Águas Belas. Brasília: FUNAI / CGMT / CGETNO / CGGAM, 2012.

DIEGUES, Antonio Carlos Sant'Ana. O mito moderno da natureza intocada. 4 Ed. São Paulo: Hucitec/Nupaub/USP, 2004.

INGOLD, Tim. Jornada ao longo de um caminho de vida: mapas, descobrirdor-caminho e navegação. Religião e Sociedade, 26 (1): 76-110, 2005.

MACIEL, Ney José Brito. Instrumentos de gestão territorial e ambiental. Brasília-DF. IEB, 2015. 48pp.

Professores/as Indígenas Kapinawá. ANDRADE, Lara Erendira A.; Mendonça, Caroline (Orgs.). Kapinawá: território, memórias e saberes. 01. ed. Olinda: CCLF, 2016. v. 1000. 120p. Disponível em: <https://1drv.ms/b/s!AoiZuL-mnp27g61BFSeGS-HV2xsLhg>. 